\title{
Kinetics of oxidation of chloroprocaine hydrochloride by N-halo-p-toluene sulfonamides in acid medium: A Mechanistic approach
}

\author{
J.P. Shubha ${ }^{* a}$, R. Manjunath ${ }^{\mathrm{a}} \&$ Puttaswamy $^{\mathrm{b}}$ \\ ${ }^{a}$ Department of Chemistry, Don Boco Institute of Technology, Mysore Road, Bangalore - 560074 \\ ${ }^{b}$ Department of Post Graduate Studies in Chemistry, Central College, Bangalore University, Bangalore 560
}

001, India

\begin{abstract}
A kinetic study of oxidation of a potent local anaesthetic chloroprocaine hydrochloride by sodium $N$ halo-p-toluenesulfonamides (chloramine-T and bromamine-T) has been carried in $\mathrm{HClO}_{4}$ medium at $303 \mathrm{~K}$. The rate shows a first-order dependence on both [oxidant $]_{o}$, and [substrate $]_{o}$, and a fractional-order dependence on acid concentration. Increase in the rate of reaction has been observed with decrease of dielectric constant of the medium by adding methanol. Variation of ionic strength and addition of p-toluenesulfonamide or $\mathrm{NaCl}$ have no significant effect on the rate. The reaction was studied at different temperatures and the activation parameters have been evaluated. The stoichiometry of the reaction was found to be 1:3 and the oxidation products were identified by spectral analysis. The experimental results have been explained by probable mechanism and the associated rate law has been deduced.
\end{abstract}

Keywords: Oxidation-kinetics, local anaesthetics, chloroprocaine hydrochloride, chloramine-T, bromamine-T, acid medium

\section{Introduction}

The sodium salts of arylhalosulfonamides generally known as organic haloamines have attracted the attention of chemists, as versatile redox titrants [1]. The diverse chemical behaviour of organic haloamines is attributed in general to their ability to act as halonium cations, hypohalites, $\mathrm{N}$-anions which act both as bases and nucleophiles and nitrenoids in limiting cases [2]. As a result, these compounds react with a wide range of functional groups and affect a variety of molecular changes. Organic haloamines are mild oxidants containing a strongly polarized $\mathrm{N}$-linked halogen which is in +1 state. The subject has been extensively reviewed and well studied $^{2-6}$. The important chlorine compound of this class is sodium N-chloro-p-toluenesulfonamide or chloramine-T (CAT), is a byproduct in the manufacture of saccharin. This reagent has been exploited as an oxidant for a variety of substrates in both acidic and alkaline media [1-12]. The bromine analogue of CAT, bromamine-T (BAT) is gaining importance as a mild oxidant and is found to be a better oxidizing agent than the chloro derivative [11-12]. This reagent can be easily prepared by the bromination of CAT. Although BAT is a better oxidant compare to CAT, an extensive literature survey reveals that only sporadic references are available about the oxidative behaviour of BAT from the kinetic and mechanistic points of view. This aroused our interest to carry out the detailed kinetic study on the oxidation of chloroprocaine hydrochloride by the closely related reagents CAT and BAT in acid medium to explore the mechanistic aspects of these oxidations and also to acess their relative rates. The studies extended to the relevant kinetic features of CAT and BAT and to identify the reactive oxidizing species of these oxidants in aqueous acidic medium.

Local anaesthetic is a type of medication used to numb areas of the body during some types of surgery. Local anaesthetic causes a complete loss of pain sensation to a specific area of your body without making you lose consciousness. It works by blocking the nerves from the affected part of your body so that signals can't reach your brain. You will not be able to feel any pain during the procedure but you may still feel some pressure or movement. It only takes a few minutes to lose feeling in the area where local anaesthetic is given [13].

Chloroprocaine, like other local anesthetics, blocks the generation and the conduction of nerve impulses, presumably by increasing the threshold for electrical excitation in the nerve, by slowing the propagation of the nerve impulse and by reducing the rate of rise of the action potential. In general, the progression of anesthesia is related to the diameter, myelination and conduction velocity of affected nerve fibers. Chloroprocaine hydrochloride (4-Amino-2-chlorobenzoic acid 2-(diethylamino) ethyl ester monohydrochloride) is an ester-type local anaesthetic agent with a rapid onset of action and a duration of anaesthesia of up to 100 minutes [14-15].

In the light of these considerations, we report herein, the hitherto unreported results on the oxidationkinetics and mechanistic aspects of chloroprocaine hydrochloride by CAT and $\mathrm{BAT}$ in $\mathrm{HClO}_{4}$ medium. The principal aim of this research is to: (i) accumulate kinetic data, (ii) elucidate suitable mechanism, (iii) deduce 
relevant rate law, (iv) identify the oxidation products, (v) compute activation parameters, and (vi) assess relative reactivity and kinetic features of CAT and BAT towards chloroprocaine in $\mathrm{HClO}_{4}$ medium.

\subsection{Materials and methods}

\section{Experimental}

Chloramine-T (E. Merck) was used as received. Bromamine-T was obtained [16] by the partial debromination of dibromamine-T (DBT) by $4 \mathrm{~mol} \mathrm{dm}^{-3} \mathrm{NaOH}$. The purity of these reagents was assayed iodometrically to determine the active halogen content. Aqueous solution of these oxidants was standardized by the iodometric method and stored in brown bottles to prevent any of its photochemical deterioration. Pharmaceutical grade chloroprocaine (gift sample) was used as received and aqueous solution of the compound was prepared fresh just before use. Solvent isotope studies were made with $\mathrm{D}_{2} \mathrm{O}(99.4 \%)$ supplied by BARC, Mumbai, India. Analytical grade chemicals and double distilled water was used throughout. The regression coefficient $(r)$ was calculated using $f_{x}-350 \mathrm{TL}$ scientific calculator

\subsection{Kinetic procedure}

Reactions were carried out under pseudo first-order conditions were maintained for the kinetic runs ([substrate $]_{\mathrm{o}}>>$ [oxidant $]_{\mathrm{o}}$ ) at constant temperature $303 \mathrm{~K}$ in glass stoppered pyrex boiling tubes coated black from outside to eliminate photochemical deterioration. Raaga digital proportional temperature controller $(\mathrm{CH}-$ 16) was used to maintain the desired temperature with an accuracy of $\pm 0.1{ }^{0} \mathrm{C}$. The requisite amounts of solutions of substrate and $\mathrm{HClO}_{4}$ solutions and water (for constant total volume) for all kinetic runs were equilibriated at $303 \mathrm{~K}$ for about $30 \mathrm{~min}$. A measured amount of oxidant also equilibriated at the same temperature was rapidly added to the reaction mixture which was periodically shaken for uniform concentration. The progress of the reaction was monitored by withdrawing measured aliquots $(5 \mathrm{ml}$ each) from the reaction mixture at regular time intervals and determined the unreacted oxidant iodometrically. The course of the reaction was studied more than two half-lives. The pseudo first-order rate constants $\left(\mathrm{k}^{\prime} \mathrm{s}^{-1}\right)$ calculated from the linear plots of $\log$ [oxidant] versus time were reproducible within $\pm 3-4 \%$.

\subsection{Stoichiometry and product analysis}

Varying ratios of oxidant to chloroprocaine hydrochloride were equilibriated at $303 \mathrm{~K}$ for $24 \mathrm{~h}$ in presence of $0.2 \mathrm{~mol} \mathrm{dm} \mathrm{HClO}_{4}$. The unreacted oxidant was determined by iodometry and the analysis showed that in both the cases one mole of chloroprocaine hydrochloride consumed three moles of oxidant and the observed reaction stoichiometry is represented in equation 1 .

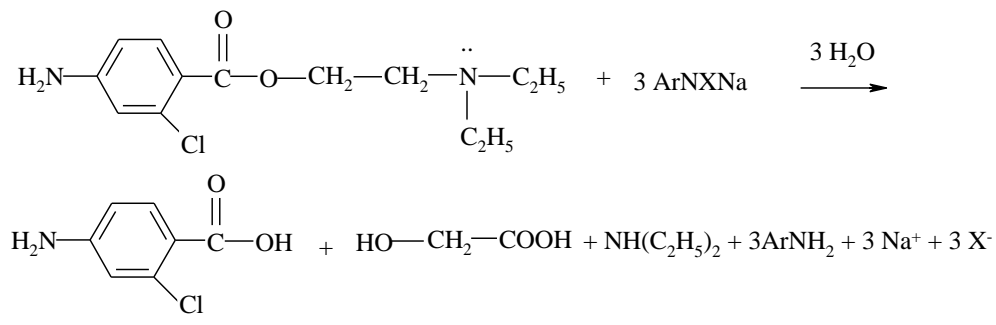

Where $\mathrm{X}=\mathrm{Cl} / \mathrm{Br}$ and $\mathrm{Ar}=\mathrm{CH}_{3} \mathrm{C}_{6} \mathrm{H}_{4} \mathrm{SO}_{2}$

After completion of the reaction, the reaction products were neutralized with acid/alkali and extracted with ether. The organic products were subjected to spot tests ${ }^{5}$ and chromatographic analysis using TLC, which revealed the formation of oxidation products as p-aminobenzoic acid, diethylamine and glycolic acid in both the media. Further, these products were confirmed by IR and mass spectral analysis.

IR spectrum was recorded on Nicolet model impact $400 \mathrm{D}$ FT-IR spectrum (KBr pellets $3 \mathrm{~cm}^{-1}$ resolution). IR spectral bands of p-aminobenzoic acid were observed at $1693 \mathrm{~cm}^{-1}(-\mathrm{C}=\mathrm{O}), 3462 \mathrm{~cm}^{-1}(-\mathrm{OH})$, and $3364 \mathrm{~cm}^{-1}$ and $3224 \mathrm{~cm}^{-1}\left(-\mathrm{NH}_{2}\right)$; Diethylamine at $3445 \mathrm{~cm}^{-1}(-\mathrm{NH}-)$; Glycolic acid at $1730 \mathrm{~cm}^{-1}(-\mathrm{C}=\mathrm{O})$ and a broad peak at $3473 \mathrm{~cm}^{-1}(-\mathrm{OH})$. GC-MS was obtained on a 17A Shimadzu gas chromatograph with a QP5050A Shimadzu mass spectrometer. The mass spectrum was obtained using the electron impact ionization technique. The mass spectrum showed a molecular ion peaks at 137, 73 and 76 amu, clearly confirming paminobenzoic acid (Figure 1), diethylamine (Figure 2) and glycolic acid (Figure 3), respectively. It was also noticed that there was no further oxidation of these products under current kinetic circumstances.

The reaction product of oxidant, p-toluenesulfonamide was extracted with ethyl acetate and detected by paper chromatography [17]. Benzyl alcohol saturated with water was used as the solvent system with $0.5 \%$ vanillin in $1 \% \mathrm{HCl}$ solution in ethanol as spray reagent $\left(\mathrm{R}_{\mathrm{f}}=0.905\right)$. Further, the molecular ion peak of 171 amu (Figure 4) confirms p-toluenesulfonamide. All other peaks observed in GC-MS can be interpreted in accordance with the observed structure. 


\section{Results and discussion}

The kinetics of oxidation of chloroprocaine hydrochloride by CAT and BAT (henceforth abbreviated as oxidant) have been investigated at several initial concentrations of the reactants, under pseudo first-order conditions of [substrate] $]_{0}>$ [oxidant] $]_{0}$, in presence of $\mathrm{HClO}_{4}$ at $303 \mathrm{~K}$ in both cases. Under the identical experimental conditions, the kinetic and mechanistic features for the oxidation of chloroprocaine hydrochloride with the closely related compounds CAT and BAT in $\mathrm{HClO}_{4}$ medium are same. But the relative rates of oxidation of chloroprocaine hydrochloride by BAT is about three-fold faster than CAT.

\subsection{Effect of reactant concentrations on the reaction rate}

The kinetics of oxidation of chloroprocaine hydrochloride by $\mathrm{CAB}$ was investigated at several initial concentrations of the reactants at $303 \mathrm{~K}$. Under pseudo first-order conditions of [substrate $]_{0}>>$ [oxidant $]_{0}$ at constant $\left[\mathrm{HClO}_{4}\right]$ and temperature, plots of log [oxidant] versus time were linear $(\mathrm{r}>0.9925)$ indicating a firstorder dependence of rate on [oxidant] $]_{0}$. The pseudo-first-order rate constants $\left(\mathrm{k}^{\prime}\right)$ calculated from these plots are given in Table 1. Further, the values of $\mathrm{k} /$ calculated from these plots are unaltered with variation of [oxidant] confirming the first-order dependence on [oxidant $]_{0}$. The rate increased with increase in [substrate $]_{0}$ (Table 1). A plot of $\log \mathrm{k}^{\prime}$ versus $\log$ [substrate] was linear $(\mathrm{r}=0.9982)$ with a unit slope indicating a first-order dependence of the rate on [substrate $]_{0}$. Values of $\mathrm{k}^{\prime}$ are increased with increase in $\left[\mathrm{HClO}_{4}\right]$, indicating a fractional-order dependence of rate on $\left[\mathrm{H}^{+}\right]($Table 1).

\subsection{Effect of $\mathrm{HClO}_{4}$ and p-toluenesulfonamide concentrations on the reaction rate}

The rate of reaction increased with increase in $\left[\mathrm{HClO}_{4}\right]$ (Table 1) and plots of $\log \mathrm{k}^{\prime}$ vs. $\log \left[\mathrm{HClO}_{4}\right]$ were linear $(\mathrm{r}>0.9986)$ with slopes of 0.68 and 0.52 for CAT and BAT, showing a fractional-order dependence on $\left[\mathrm{HClO}_{4}\right]$. Addition of p-toluenesulfonamide $\left(\mathrm{ArNH}_{2}\right)$ to the reaction mixture $\left(5.0 \times 10^{-3} \mathrm{~mol} \mathrm{dm}^{-3}\right)$ did not affect the rate significantly indicates that $\mathrm{ArNH}_{2}$ is not involved in any step prior to the rate determining step of the proposed scheme.

\subsection{Effect of ionic strength and halide ions on the reaction rate}

Effect of ionic strength on the reaction rate was investigated in presence of $0.1 \mathrm{~mol} \mathrm{dm}^{-3}$ sodium perchlorate, keeping all other experimental conditions constant. It was found that addition of $\mathrm{NaClO}_{4}$ showed insignificant effect on the reaction rate, demonstrating the involvement of non - ionic species in the rate determining step. Subsequently, the ionic strength of the reaction mixture was not fixed for kinetic runs. Further, addition of $\mathrm{Br}^{-}$or $\mathrm{Cl}^{-}$ions in the form of their sodium salts at the concentration of $5.0 \times 10^{-3} \mathrm{~mol} \mathrm{dm}^{-3}$ showed a negligible effect on the reaction rate suggests that no inter halogen or chlorine (or bromine) is formed and that there is a direct interaction of the oxidizing species with the substrate.

\subsection{Effect of dielectric constant and solvent isotope on the reaction rate}

Rate studies were carried out in water-MeOH mixtures having different compositions ( 0 - $30 \% \mathrm{v} / \mathrm{v})$, thereby varying the dielectric constant (D) of the medium. It was observed that an increase in methanol composition in the reaction system increased the reaction rate (Table 2) and a plot of log $\mathrm{k}^{\prime}$ versus 1/D was linear (Figure1; $r=0.9922$ ) with a positive slope. The values of permittivity (dielectric constant) for $\mathrm{MeOH}-$ water mixtures reported in the literature were employed ${ }^{14}$. Blank experiments run with methanol indicated negligible oxidation under the experimental conditions employed.

As the oxidation of chloroprocaine hydrochloride by CAT and BAT was accelerated by $\mathrm{H}^{+}$ions, the solvent isotope effect was studied in $\mathrm{D}_{2} \mathrm{O}$ as the solvent medium for both the oxidants. The rate constants for CAT and BAT revealed that $\mathrm{k}^{\prime}\left(\mathrm{H}_{2} \mathrm{O}\right)$ was equal to $1.88 \times 10^{-4} \mathrm{~s}^{-1}$ and $6.32 \times 10^{-4} \mathrm{~s}^{-1}$ and $\mathrm{k}^{\prime}\left(\mathrm{D}_{2} \mathrm{O}\right)$ was $2.83 \times 10^{-4}$ and $9.02 \mathrm{x}$ $10^{-4} \mathrm{~s}^{-1}$ respectively. Thus the solvent isotope effect $\mathrm{k}^{\prime}\left(\mathrm{H}_{2} \mathrm{O}\right) / \mathrm{k}^{\prime}\left(\mathrm{D}_{2} \mathrm{O}\right)$ was found to be 0.66 and 0.70 for CAT and BAT.

\subsection{Effect of temperature on the reaction rate}

The reaction was studied at different temperatures (283-313 K), keeping other experimental conditions constant. From Arrhenius plots of $\log \mathrm{k}^{\prime}$ vs. $1 / \mathrm{T}(\mathrm{r}>0.9934)$, composite activation parameters $\left(\mathrm{E}_{\mathrm{a}}, \Delta \mathrm{H}^{\neq}, \Delta \mathrm{S}^{\neq}\right.$, $\Delta \mathrm{G}^{\neq}$and $\log$ A) were computed for the oxidation of substrate by CAT and BAT. These data are summarized in Table 2.

\subsection{Polymerization study}

Alkene monomers such as acrylonitrile and freshly prepared $10 \%$ acryamide solution were added to the reaction mixture to initiate polymerization by free radicals formed in situ. The lack of polymerization indicated the absence of free radicals in the reaction mixture. This clearly ruled out the possibility of free radical mechanism. The controlled experiments were also performed under similar reaction conditions without oxidant. 


\subsection{Organic N-haloamines}

Organic N-haloamines are sources of positive halogens and these reagents have been exploited as oxidant for a variety of substrates in both acidic and alkaline media [1-3]. Since organic N-haloamines have similar chemical properties, it is expected that identical equilibria exist in aqueous acidic and basic solutions of these compounds [18-19]. Chloramine-T and bromamine-T act as oxidizing agents in acidic and alkaline media ${ }^{2}$ with a two electron change per mole giving p-toluenesulfonamide (PTS) and $\mathrm{NaCl}$ or $\mathrm{NaBr}$. The redox potential of CAT-PTS couple is $\mathrm{pH}$ dependent [20] and decreases with increase in $\mathrm{pH}$ of the medium $\left(\mathrm{E}_{\text {redox }} 1.138 \mathrm{~V}\right.$, $1.778 \mathrm{~V}, 0.614 \mathrm{~V}$ and $0.5 \mathrm{~V}$ at $\mathrm{pH} 0.65,7.0,9.7$ and 12 , respectively). In view of the homogeneity in properties of CAT and BAT, similar redox potential behaviour can be expected for BAT also. The nature of the active oxidizing species and mechanism depends on the nature of halogen atom, the groups attached to the nitrogen and the reaction condition. The species responsible for such oxidizing character may be different depending on the $\mathrm{pH}$ of the medium.

\subsection{Reactive species of CAT and BAT}

Organic N-haloamines are sources of positive halogens and these reagents have been exploited as oxidant for a variety of substrates in both acidic and alkaline media [11-13]. Since organic N-haloamines have analogous chemical properties, it is predicted that identical equilibria exist in aqueous acidic and basic solutions of these compounds [18-19]. Chloramine-T and bromamine-T act as oxidizing agents in acidic and alkaline media with a two electron change per mole giving p-toluenesulfonamide (PTS) and $\mathrm{NaCl}$ or $\mathrm{NaBr}$. The redox potential of CAT-PTS couple is $\mathrm{pH}$ dependent and decreases with increase in $\mathrm{pH}$ of the medium $\left(\mathrm{E}_{\text {redox }}=1.138\right.$ $\mathrm{V}, 1.778 \mathrm{~V}, 0.614 \mathrm{~V}$ and $0.5 \mathrm{~V}$ at $\mathrm{pH}=0.65,7.00,9.70$ and 12.00 , respectively). In view of the homogeneity in properties of CAT and BAT, similar redox potential behavior can be expected for BAT also. The nature of the active oxidizing species and mechanism depends on the nature of halogen atom, the groups attached to the nitrogen and the reaction condition. The species accountable for such oxidizing character may be different depending on the $\mathrm{pH}$ of the medium.

$\mathrm{ArNXNa} \rightleftharpoons \mathrm{ArNX}^{-}+\mathrm{Na}^{+}$
$\mathrm{ArNX}+\mathrm{H}^{+} \rightleftharpoons \mathrm{ArNHX}$
$2 \mathrm{ArNHX} \rightleftharpoons \mathrm{ArNH}_{2}+\mathrm{ArNX}_{2}$
$\mathrm{ArNX}_{2}+\mathrm{H}_{2} \mathrm{O} \rightleftharpoons \mathrm{ArNHX}^{2} \mathrm{HOX}$
$\mathrm{ArNHX}+\mathrm{H}_{2} \mathrm{O} \rightleftharpoons \mathrm{ArNH}_{2}+\mathrm{HOX}$
$\mathrm{HOX} \rightleftharpoons \mathrm{OX}^{-}$
$\mathrm{HOX}+\mathrm{H}^{+} \rightleftharpoons \mathrm{H}_{2} \rightleftharpoons \mathrm{OX}^{+}$

Therefore, the possible oxidizing species in acid solution of oxidant are ArNHX, ArNX, $\mathrm{HOX}$ and possibly $\mathrm{H}_{2} \mathrm{OX}^{+}$and in alkaline solutions they are ArNHX, ArNX, HOX and OX. The first-order dependence of rate on [oxidant] ${ }_{o}$ and the addition of p-toluenesulfonamide $\left(\mathrm{ArNH}_{2}\right)$ having no effect on the reaction rate, both indicate that $\mathrm{ArNX}_{2}$ and HOX may not be the reactive species [Eqs (4) and (6)]. Further, these species are present in very low concentrations at the experimental conditions employed [21-22]. Since pKa of PhSO2NHBr is 4.95 at $298 \mathrm{~K}$, it is likely that under the present acidic conditions CAT and BAT may exist [18] primarily as ArNHX and any dependence of rate on $\left[\mathrm{H}^{+}\right]$could be attributed to the addition of a second proton to ArNHX. Furthermore, Narayanan and Rao [23] and Subhashini et al [24] have reported that monochloramines can be further protonated at $\mathrm{pH} 2$ as shown in eq. (9) and eq. (10) for chloramine-T and chloramine-B, respectively.

$$
\begin{aligned}
& \mathrm{ArNHCl}+\mathrm{H}^{+} \rightleftharpoons \mathrm{ArNH}_{2} \mathrm{Cl}^{+} \\
& \mathrm{PhSO}_{2} \mathrm{NHCl}+\mathrm{H}^{+} \rightleftharpoons \mathrm{PhSO}_{2} \mathrm{NH}_{2} \mathrm{Cl}^{+}
\end{aligned}
$$

The second protonation constants for CAT and CAB are $102 \mathrm{M}^{-1}$ and $61 \pm 5 \mathrm{M}^{-1}$ respectively at $298 \mathrm{~K}$. Because organic haloamines have similar chemical properties, it is reasonable to expect the formation of an identical species of the type $\mathrm{ArNH}_{2} \mathrm{Br}^{+}$for BAT also. In the present investigations, the acceleration of rate by $\mathrm{H}^{+}$ ion indicates that $\mathrm{ArNH}_{2} \mathrm{X}^{+}$is the active oxidizing species. Further, variations of ionic strength of the medium or addition of the reaction product, p-toluenesulfonamide have virtually no effect on the rate. Based on the preceding discussion and experimental facts, Scheme 1 is proposed to explain the reaction mechanism for the oxidation of chloroprocaine hydrochloride by CAT and $\mathrm{BAT}$ in $\mathrm{HClO}_{4}$ medium. 


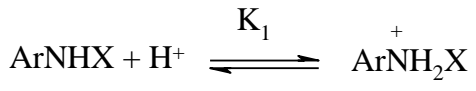

$\underset{+}{\mathrm{ArNH}_{2} \mathrm{X}}+$ substrate $\stackrel{\mathrm{k}_{2}}{\longrightarrow} \mathrm{X}$

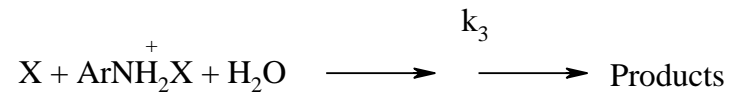

...(i) fast

...(ii) slow and rds

...(iii) fast

Scheme 1. A general reaction scheme for the oxidation of chloroprocaine hydrochloride by CAT and BAT acid medium.

In scheme 2, an initial equilibrium acid accelerating step (step (i)), the protonated acid further protonates to form diprotonated species. In the slow and rate determining step (step (ii)) the diprotonated species reacts with substrate to form a complex $(\mathrm{X})$. This complex $\mathrm{X}$ consumes another two moles of the oxidant yields the products followed by several steps. Two moles of the oxidant are consumed to yield the ultimate products. Based on Scheme 1 the following rate law has been proposed, which is in good agreement with the experimental results.

$$
\text { rate }=\frac{\left.\mathrm{K}_{1} \mathrm{k}_{2} \text { [oxidant }\right]_{\mathrm{t}}[\text { substrate }]\left[\mathrm{H}^{+}\right]}{1+\mathrm{K}_{1}\left[\mathrm{H}^{+}\right]}
$$

Rate law (11) is in good agreement with the experimental results observed.

Reactions in aqueous medium that are susceptible to acid-base catalysis have been studied in heavy water $\left(\mathrm{D}_{2} \mathrm{O}\right)$ after equilibrium. Since most oxidation reactions of organic compounds involve the cleavage of $C$ $\mathrm{H}$ bond, deuterium isotope effect on such reactions gives information regarding the nature of the ratedetermining step. In the present investigations, solvent isotope studies have shown that the rate of reaction is higher in $\mathrm{D}_{2} \mathrm{O}$ medium. For a reaction involving a fast equilibrium with $\mathrm{H}^{+}$or $\mathrm{OH}^{-}$ion transfer, the rate increases in $\mathrm{D}_{2} \mathrm{O}$ medium since $\mathrm{D}_{3} \mathrm{O}^{+}$and $\mathrm{OD}^{-}$are a stronger acid and a stronger base respectively, than $\mathrm{H}_{3} \mathrm{O}^{+}$and $\mathrm{OH}^{-}$ ions [25-30]. The observed solvent isotope effect of $\mathrm{k}^{\prime}\left(\mathrm{H}_{2} \mathrm{O}\right) / \mathrm{k}^{\prime}\left(\mathrm{D}_{2} \mathrm{O}\right)<1$ is due to the greater acidity of $\mathrm{D}_{3} \mathrm{O}^{+}$ compared to $\mathrm{H}_{3} \mathrm{O}^{+}$. However, the magnitude of increase in rate in $\mathrm{D}_{2} \mathrm{O}$ is small as compared to the expected value which is 2-3 times greater. This may be due to the fractional order dependence of the rate on $\left[\mathrm{H}^{+}\right]$. Hence, this observation supports the proposed mechanism.

The effect of varying solvent composition on the reaction kinetics has been described in detail in the well-known monographs [31-32]. For a limiting case of zero angle of approach between two dipoles or an iondipole system, Amis [31] has shown that a plot of $\log \mathrm{k}^{\prime}$ versus 1/D gives a straight line, with a negative slope for a reaction between a negative ion and a dipole or between two dipoles, while a positive slope results for a positive ion-dipole interaction. The latter concept agrees with the present observations, where a positive ion and a dipole are involved in the rate determining step of Scheme 2.

The reaction product, p-toluenesulfonamide $\left(\mathrm{ArNH}_{2}\right)$ does not influence the rate showing that it is not involved in a pre-equilibrium. Addition of chloride ions had no effect on the rate indicating that no interhalogen or free chlorine is formed. All these observations also confirm the proposed mechanism.

\subsection{Relative reactivity of CAT and BAT}

A comparison of the rates of reaction of CAT and BAT shows that the oxidation of diclofenac is about three-fold faster in BAT compared to CAT, under identical set of experimental conditions. This is endorsed by the relative magnitudes of activation energies (Table 2). This trend may be attributed to the difference in elctrophilicities of the halocations, $\mathrm{Cl}^{+}$and $\mathrm{Br}^{+}$ions, involved in the oxidation processes and, is also related to the ease with which these species are generated in reactions. In these oxidation reactions, the electronegativity values of $\mathrm{Br}^{+}$and $\mathrm{Cl}^{+}$play a vital role. Bromine has the elctronegativity of 2.7 , while chlorine has a higher value of 2.8. As the elcetronegativity increases the electropositive nature decreases. Since the halo cations are the reactive species in these oxidation reactions, the electropositive nature is in the order: $\mathrm{Br}>\mathrm{Cl}$. Therefore the reactivity of BAT is more compared to CAT. This trend may also be due to the moderate difference in the van der Waals's radii of bromine and chlorine. A similar behaviour has been noted [5] in the oxidation of several other substrates using CAT and BAT. The facts furnished in the present research and the literature reports [3334] led to conclude that BAT is a stronger oxidant compared to CAT.

The proposed mechanism is also supported by the moderate values of energy of activation and other thermodynamic parameters. The energy of activation is highest for the slowest reaction and vice-versa indicating that the reaction is enthalpy controlled (Table 2). The positive values of $\Delta \mathrm{H}^{\neq}$and $\Delta \mathrm{G}^{\neq}$indicate that the 
transition state is highly solvated. The negative values of $\Delta \mathrm{S}^{\neq}$suggest the formation of a rigid associative transition state with a few degrees of freedom in both cases. Further, the comparable values of $\Delta \mathrm{G}^{\neq}$signify the same type of the reaction mechanism could be operative for the oxidation of chloroprocaine hydrochloride by CAT and BAT in acid medium. The values of frequency factor (A) specify the frequency of collisions and the orientation of reacting molecules. The ineffectiveness of the additions of p-toluenesulfonamide, neutral salts and halide ions on the rate of the reaction are in agreement with the proposed mechanism and the derived rate law.

\section{Conclusions}

The kinetics of oxidation of chloroprocaine hydrohloride by CAT and BAT has been studied at $303 \mathrm{~K}$. The reaction follows the rate law, rate $=\mathrm{k}[\mathrm{CAB}]_{\mathrm{o}}[$ substrate $]\left[\mathrm{H}^{+}\right]^{0.47}$. On the basis of experimental results a suitable mechanism and appropriate rate law have been derived. The relevant rate law has been designed. Under identical experimental conditions, the rate of oxidation of chloroprocaine hydrochloride is about three-fold faster with BAT as compared to CAT. This may be attributed to the difference in electrophilicities of $\mathrm{Cl}^{+}$and $\mathrm{Br}^{+}$ions and also the van der Waal's radii of chlorine and bromine.

\section{Acknowledgement}

The authors are thankful to the Principal and the Management, Don Bosco Institute of Technology for constant encouragement and facilities.

[1]. Campbell MM, Johnson G, Chem Rev, 78 (1978) 65.

[2]. Banerji KK, Jayaram B, Mahadevappa D S, J Sci Ind Res, 46 (1987) 65.

[3]. Agarwal MC, Upadhyaya SK, J Sci Ind Res, 49 (1990)13.

[4]. Armesto XL, Canle L, Garia MV, Santaballa JA, Chem Soc Rev, 27 (1998) 453.

[5]. Kolvari EE, Ghorbani-Chogamarani A, Salehi P, Shirini F, Zolfigol MA, J. Iran. Chem. Soc, 4 (2007) 126.

[6]. Murthy ARV, Rao BS, (1952) Proc. Indian Acad. Sci., 35, 69.

[7]. Vinod KN, Puttaswamy, Gowda KNN, J Mol Catal A: Chem, 298 (2009) 60.

[8]. Meenakshisundaram SP, Sockalingam R, J Mol Catal A: Chem, 162 (2000) 269

[9]. Puttaswamy, Shubha JP, Indian J. Chem 45(A) (2006) 2412-2417.

[10]. Puttaswamy, Anu S, Shubha JP, J Mol Catal A: Chem, 332 (2010) 113.

[11]. Puttaswamy, Shubha JP. AIChE Journal, 55(12) (2009) 3234-3240

[12]. Shubha JP., K. Vinutha, Puttaswamy, Eur. J. Chem. 4 (4) (2013) 408-413

[13]. Ashutosh Kar, Medicinal Chemistry, Wiley Eastern, New Delhi, 1993, 44

[14]. Wilson CO, Gisvold O, Doerge RF, Text book of organic medicinal and pharmaceutical chemistry, $6^{\text {th }}$ Ed., J.B. Lippincott Co, Toronto, 1971, 662.

[15]. Cousins MJ, Cousins and Bridenbaugh's Neural Blockade in Clinical Anesthesia and Pain, Lippincott Co, Toronto, (2008) 106.

[16]. Nair CGR, Lalithakumari R, Indrasenan P. Talanta. 1978:25:525-527.

[17]. Puttaswamy, Anuradha TM, Ramachandrappa R, Gowda NMM. Int J Chem Kinet. 2000:32:221-230

[18]. Bishop E, Jennings VJ, Talanta, 1 (1958) 197.

[19]. Hardy FF, Johnston JP, J Chem Soc, Perkin Trans. 2, (1973) 742.

[20]. Murthy ARV, Rao BS. Proc Indian Acad Sci. 1952:35:69-72.

[21]. Higuchi K, Ikeda K, Hussain A, J Chem Soc B, (1968) 1031.

[22]. Pryde BG, Soper FD. J Chem Soc. 1931:1510-1512.

[23]. Narayanan, S. S.; Rao, V. R. S. Radio Chim. Acta 1983, 32, 211.

[24]. Subhashini, M.; Subramanian, M.; Rao, V. R. S. Talanta 1985, 32, 1082

[25]. Collins, C. J.; Bowman, N. S. Isotope Effects in Chemical Reactions; Van Nostrand Reinhold, New York, 1970; p 1267.

[26]. Kohen, A.; Limbach, H. H. Isptope Effects in Chemistry and Biology; CRC Press: Florida, 2006; p 827.

[27]. Moelwyn-Hughes, E. A. The Kinetics of Reaction in Solutions; Clarender Press: Oxford, 1947; p 374.

[28]. Benson, S. W. The Foundations of Chemical Kinetics; McGraw-Hill: New York, 1960; p 19.

[29]. Frost, A. A.; Pearson, R. G. Kinetics and Mechanism; Wiley: New York, 1961; p 135.

[30]. Laidler, K. J. Chemical Kinetics; Tata Mc Graw-Hill: New Delhi, 1995; p 211.

[31]. Amis, E. S. Solvent Effects on Reaction Rates and Mechanisms; Academic Press: New York, 1966; p 1672.

[32]. Gilliom, R. D. Introduction to Physical Organic Chemistry; Addison-Wesley: London, 1970; p 144

[33]. Puttaswamy and J. P. Shubha Bull. Korean Chem. Soc. 2009, Vol. 30, No. 9

[34]. J.P. Shubha, K. Vinutha, Puttaswamy, European Journal of Chemistry 4 (4) (2013) 408-413

Table 1. Effect of variation of oxidant, substrate and $\mathrm{HClO}_{4}$ concentrations on the reaction rate at $293 \mathrm{~K}$.

\begin{tabular}{|ccccc|}
\hline $10^{4}[\text { oxidant }]_{\mathrm{o}}$ & $10^{3}\left[\right.$ substrate $_{\mathrm{o}}$ & $10^{3}\left[\mathrm{HClO}_{4}\right]$ & $10^{4} k^{\prime}\left(\mathrm{s}^{-1}\right)$ \\
\hline$\left(\mathrm{mol} \mathrm{dm}^{-3}\right)$ & $\left(\mathrm{mol} \mathrm{dm}^{-3}\right)$ & $\left(\mathrm{mol} \mathrm{dm}^{-3}\right)$ & CAT & BAT \\
\hline 0.5 & 2.0 & & 1.82 & 6.41 \\
\hline 1.0 & 2.0 & 0.5 & 1.86 & 6.25 \\
\hline 1.8 & 2.0 & 0.5 & 1.88 & 6.32 \\
\hline 3.6 & 2.0 & 0.5 & 1.84 & 6.30 \\
\hline 5.0 & 2.0 & 0.5 & 1.89 & 6.28 \\
\hline 1.8 & 0.5 & 0.5 & 1.09 & 2.78 \\
\hline
\end{tabular}


Kinetics of oxidation of chloroprocaine hydrochloride by $N$-halo-p-toluene sulfonamides in ....

\begin{tabular}{|lllll|}
\hline 1.8 & 1.0 & 0.5 & 1.39 & 4.57 \\
\hline 1.8 & 2.0 & 0.5 & 1.88 & 6.32 \\
\hline 1.8 & 4.0 & 0.5 & 2.50 & 8.48 \\
\hline 1.8 & 8.0 & 0.5 & 3.50 & 12.7 \\
\hline 1.8 & 2.0 & 0.1 & 0.76 & 2.98 \\
\hline 1.8 & 2.0 & 0.2 & 1.22 & 4.13 \\
\hline 1.8 & 2.0 & 0.5 & 1.88 & 6.32 \\
\hline 1.8 & 2.0 & 1.0 & 2.91 & 8.96 \\
\hline 1.8 & 2.0 & 2.0 & 4.22 & 12.1 \\
\hline
\end{tabular}

Table 2. Temperature dependence on the reaction rate and activation parameters for the oxidation of chloroprocaine hydrochloride by CAT and BAT in acid Medium

\begin{tabular}{|ccc|}
\hline Temperature $(\mathrm{K})$ & $10^{4} k^{\prime}\left(\mathrm{s}^{-1}\right)$ & $10^{4} k^{\prime}\left(\mathrm{s}^{-1}\right)$ \\
\hline 283 & CAT & BAT \\
\hline 288 & 1.09 & 2.87 \\
\hline 293 & 1.39 & 3.92 \\
\hline 303 & 1.88 & 6.32 \\
\hline 313 & 2.50 & 11.7 \\
\hline $\mathrm{E}_{\mathrm{a}}\left(\mathrm{kJ} \mathrm{mol}^{-1}\right)$ & 3.50 & 23.2 \\
\hline$\Delta H^{\ddagger}\left(\mathrm{kJ} \mathrm{mol}^{-1}\right)$ & 57.9 & 43.5 \\
\hline$\Delta G^{\ddagger}\left(\mathrm{kJ} \mathrm{mol}^{-1}\right)$ & 56.0 & 41.5 \\
\hline$\Delta S^{\ddagger}\left(\mathrm{JK}^{-1} \mathrm{~mol}^{-1}\right)$ & 74.0 & 71.7 \\
\hline Log A & -61.1 & -120 \\
\hline$[\text { oxidant }]_{\mathrm{o}}=1.8 \times 10^{-4} \mathrm{~mol} \mathrm{dm}^{-3} ;[\text { substrate }]_{\mathrm{o}}=2.0 \times 10^{-3} \mathrm{~mol} \mathrm{dm}^{-3} ;\left[\mathrm{HClO}_{4}\right]=0.5 \times 10^{-3} \mathrm{~mol} \mathrm{dm}^{-3}$. \\
\hline
\end{tabular}

Table 3 - Effect of varying dielectric constant on the reaction rate.

\begin{tabular}{|l|ccc|}
\hline$\% \mathrm{MeOH}(\mathrm{v} / \mathrm{v})$ & \multicolumn{3}{c|}{$10^{4} k^{\prime}\left(\mathrm{s}^{-1}\right)$} \\
\hline \multirow{4}{*}{} & & CAT & BAT \\
\cline { 2 - 4 } & 0 & 1.88 & 6.32 \\
\cline { 2 - 4 } & 5 & 2.18 & 7.26 \\
\cline { 2 - 4 } & 10 & 3.59 & 8.42 \\
\cline { 2 - 4 } & 20 & 5.74 & 9.26 \\
\cline { 2 - 4 } & 40 & 6.42 & 10.7 \\
\hline
\end{tabular}

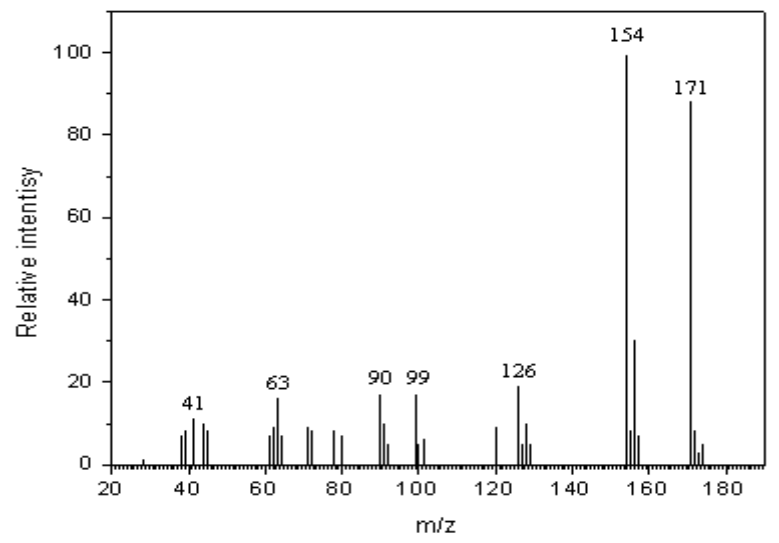

Figure 1. GC-Mass spectrum of o-chloro-p-aminobenzoic acid with its molecular ion peak at $171 \mathrm{amu}$.

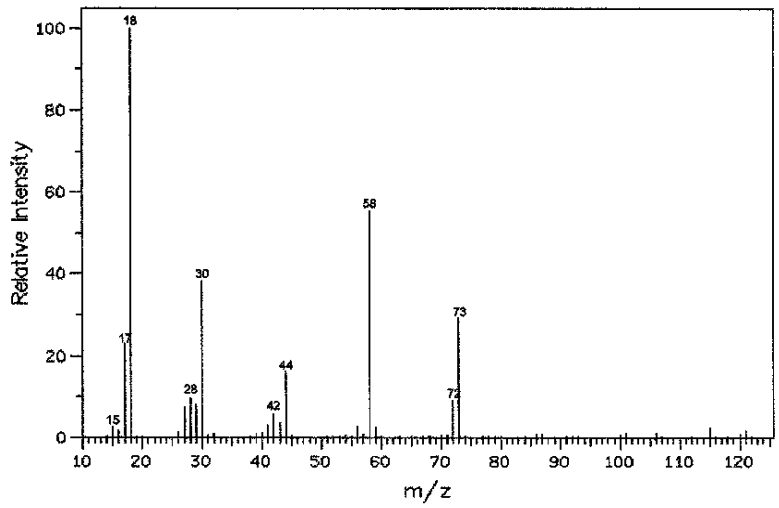

Figure 2. GC-Mass spectrum of diethylamine with its molecular ion peak at $73 \mathrm{amu}$. 


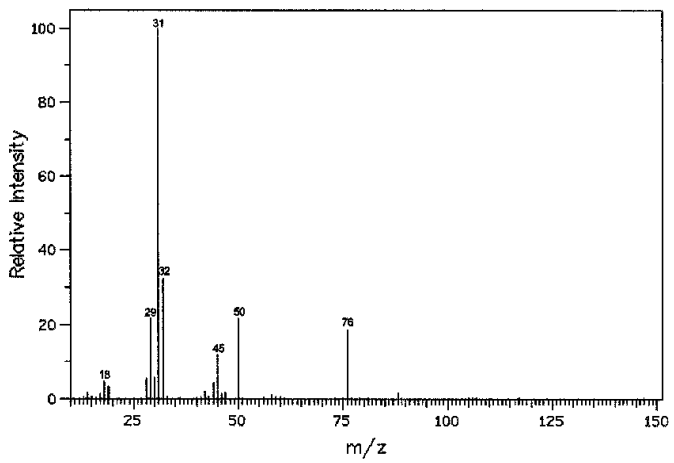

Figure 3. GC-Mass spectrum of glycolic acid with its molecular ion peak at $76 \mathrm{amu}$.

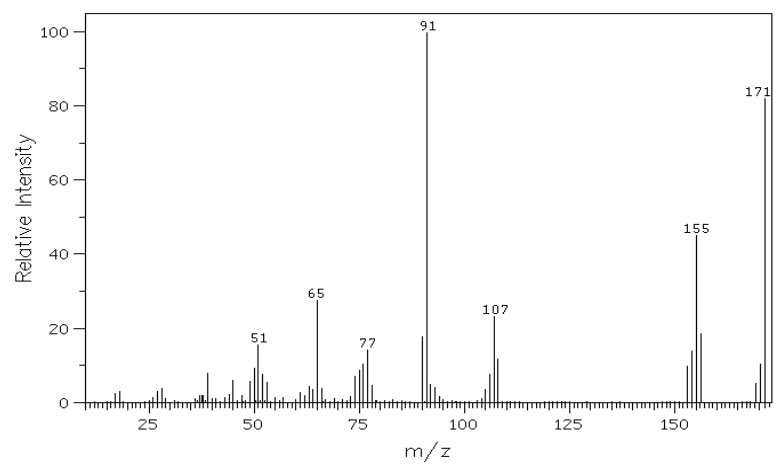

Figure 4. GC-Mass spectrum of p-toluenesulfonamide with its molecular ion peak at $171 \mathrm{amu}$.

(i) $\mathrm{ArNHX}+\mathrm{H}^{+} \stackrel{\mathrm{K}_{1}}{\rightleftharpoons} \stackrel{+}{\rightleftharpoons} \mathrm{ArNH}_{2} \mathrm{X}$
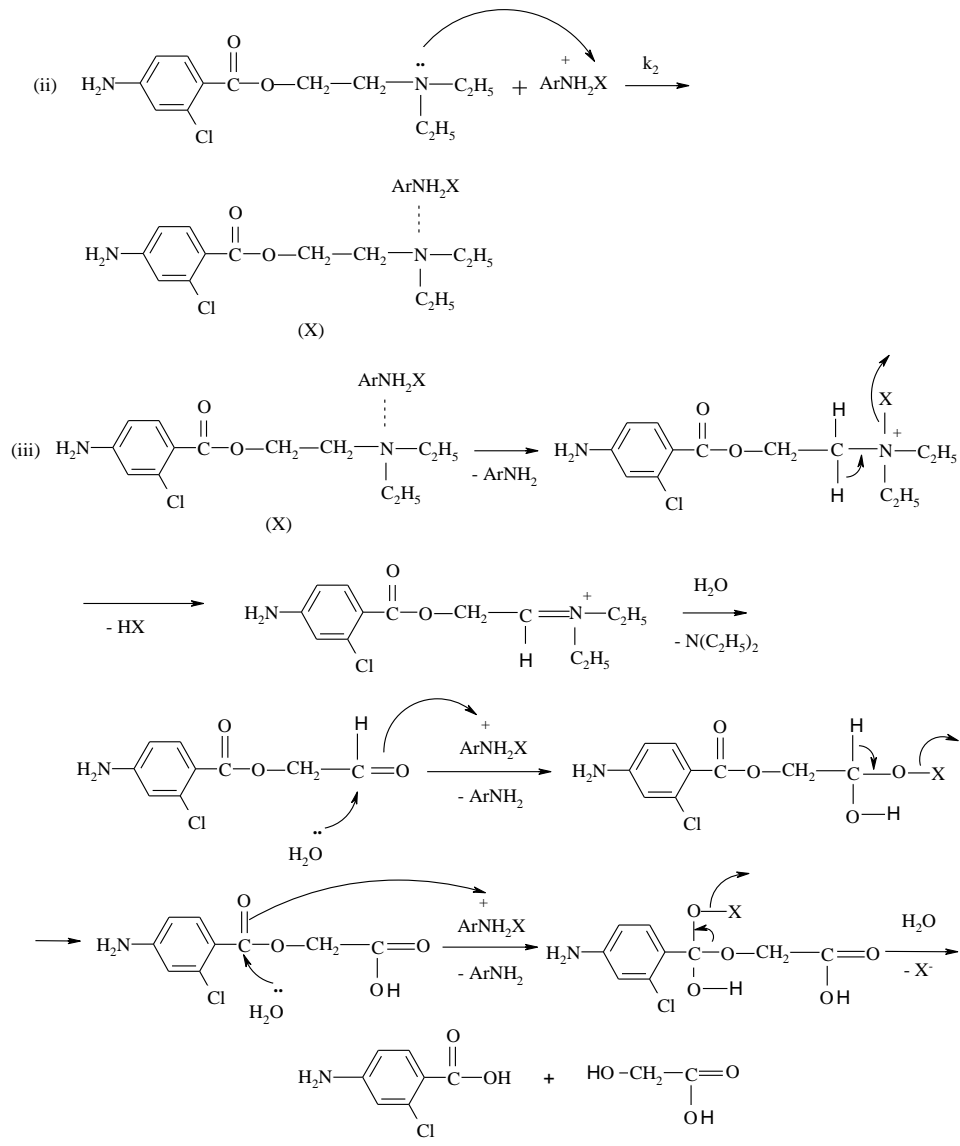

Scheme 2. Detailed mechanistic interpretation for the oxidation of chloroprocaine hydrochloride by CAT and BAT in acid medium. 